\title{
Transapical transcatheter aortic valve implantation using the J-Valve system: A 1-year follow-up study
}

\author{
Xiang Luo, MD, ${ }^{\mathrm{a}} \mathrm{Xu}$ Wang, MD, ${ }^{\mathrm{a}}$ Xuan Li, MD, ${ }^{\mathrm{a}}$ Xin Wang, MD, ${ }^{\mathrm{a}}$ Fei Xu, MD, ${ }^{\mathrm{a}}$ Mingzheng Liu, MD, \\ Bing Yu, MD, ${ }^{\mathrm{a}}$ Fei Li, MD, ${ }^{\mathrm{a}}$ Minghui Tong, $\mathrm{MD},{ }^{\mathrm{a}}$ and Wei Wang, MD, $\mathrm{PhD}{ }^{\mathrm{a}}$
}

\begin{abstract}
Objective: Transcatheter aortic valve implantation has become a routine procedure to treat screened inoperable or high-risk patients. In this study, we present the first outcome of echocardiographic midterm using a new second-generation transcatheter aortic valve implantation system, the J-Valve system (Jie Cheng Medical Technologies, Suzhou, China), in patients with aortic stenosis or aortic regurgitation.
\end{abstract}

Methods: From July 2014 to June 2015, 21 patients with isolated aortic valve disease at high risk for open surgery received transapical transcatheter aortic valve implantation using the J-Valve system. The primary end point was a combined efficacy end point after 1 year, which included all-cause mortality after more than 30 days and failure of current therapy for aortic stenosis or aortic regurgitation requiring hospitalization for symptoms of valve-related cardiac decompensation or prosthetic heart valve dysfunction. Secondary end points were cardiovascular mortality, major stroke, and life-threatening, disabling, or major bleeding after 6 and 12 months.

Results: The mean age of the study cohort was $75.52 \pm 5.22$ years, the European System for Cardiac Operative Risk Evaluation II score was $11.33 \% \pm 1.28 \%$, and the mean logistic European System for Cardiac Operative Risk Evaluation I score was $31.13 \% \pm 9.68 \%$. Transcatheter aortic valve implantation with the J-Valve system was successfully performed in 19 of the 21 patients $(90.5 \%)$. For patients with aortic stenosis, 12-month follow-up echocardiography demonstrated an increase in mean effective valve area from $0.62 \pm 0.17 \mathrm{~cm}^{2}$ to $1.52 \pm 0.35 \mathrm{~cm}^{2}$ and a decrease in transvalvular mean gradient from $61 \pm 15 \mathrm{~mm} \mathrm{Hg}$ to $18 \pm 9 \mathrm{~mm} \mathrm{Hg}$. All surviving patients $(\mathrm{n}=18)$ reported improvements in at least 1 of the New York Heart Association classes. The combined ratio of successful implantation and absence of adverse events in our cohort $(n=21)$ was $76.19 \%$.

Conclusions: The J-Valve system exhibits a convincing midterm performance and is a safe and feasible procedure with low perioperative and postoperative complications. (J Thorac Cardiovasc Surg 2017;154:46-55)

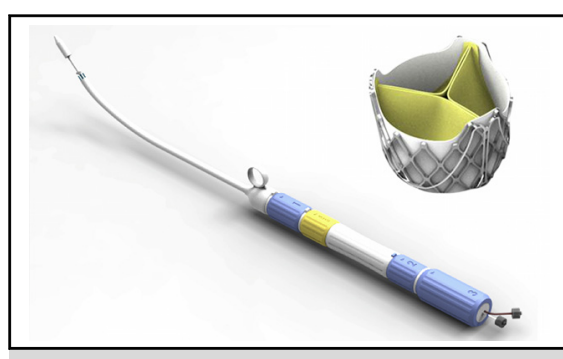

A new second-generation TAVI system: the J-Valve system (Jie Cheng Medical Technologies, Suzhou, China).

\section{Central Message}

Three U-shaped "graspers" serve as an anatomically oriented device to achieve "selfpositioning." The flexible tip of the delivery system provides better angulation during implantation.

\section{Perspective}

We present the first midterm outcome obtained using a new second-generation TAVI system, the J-Valve system (Jie Cheng Medical Technologies, Suzhou, China), in high-risk or inoperable patients with AS or AR. The study results have provided strong support for the safety and feasibility of the J-Valve system and provide evidence regarding its excellent performance in terms of enhanced echocardiographic parameters and significant NYHA classification improvement in patients.

See Editorial Commentary page 56.
Since the first transcatheter aortic valve implantation (TAVI) was performed in 2002, the TAVI procedure has been established as a safe and suitable procedure for inoperable or high-risk patients with aortic stenosis (AS) who

From the Departments of ${ }^{\mathrm{a} C}$ Cardiovascular Surgery and ${ }^{\mathrm{b}}$ Anesthesiology, National Center for Cardiovascular Disease and Fuwai Hospital, Chinese Academy of Medical Sciences, Peking Union Medical College, Beijing, People's Republic of China.

Received for publication Aug 19, 2016; revisions received Feb 6, 2017; accepted for publication March 13, 2017; available ahead of print April 21, 2017.

Address for reprints: Wei Wang, MD, PhD, 167 Beilishi Rd, Xicheng District, Beijing 100037, People's Republic of China (E-mail: drweiwang0728@hotmail.com). 0022-5223/\$36.00

Copyright (c) 2017 by The American Association for Thoracic Surgery http://dx.doi.org/10.1016/j.jtcvs.2017.03.054 are not amenable to conventional heart surgeries. ${ }^{1,2}$ In recent years, with the development of several types of second-generation TAVI devices, such as the JenaValve (JenaValve Technology, Inc, Irvine, Calif), the Symetis Acurate (Symetis SA, Ecublens, Switzerland), and the Medtronic Engager (Medtronic Inc, Minneapolis, Minn),

Scanning this QR code will take you to a supplemental video for the article. 


\section{Abbreviations and Acronyms \\ AR $=$ aortic regurgitation \\ AS $=$ aortic stenosis \\ CTA $=$ computed tomography angiography \\ euroSCORE $=$ European System for Cardiac \\ Operative Risk Evaluation \\ IQR = interquartile range \\ NYHA $=$ New York Heart Association \\ TAVI $=$ transcatheter aortic valve implantation \\ TTE $=$ transthoracic echocardiography}

TAVI indication has been expanded to inoperable or high-risk patients with aortic regurgitation (AR) but without annular or leaflet calcification. ${ }^{3}$

Observational studies have shown that paravalvular leakage of grade 2 or more is a negative predictor for successful long-term outcome in patients undergoing TAVI. ${ }^{6}$ The development of the second-generation TAVI valves has improved outcomes related to TAVI-related issues, such as paravalvular leakage, annular rupture, ostial encroachment, and rhythm disorders. The improvement in clinical results and the reduction of the degree of significant paravalvular leakage have been made possible by more accurate anatomic positioning, better anchoring of the prosthesis, and improved delivery systems. The new second-generation JenaValve transapical TAVI system has shown low perioperative and postoperative complications and a convincing midterm performance of the prosthesis. ${ }^{7}$

The J-Valve system (Jie Cheng Medical Technologies, Suzhou, China) is another newly developed secondgeneration, self-expandable TAVI device that is designed for transapical implantation. The device consists of a porcine root valve mounted on a low profile self-expanding nitinol stent, featuring 3 U-shaped anatomically oriented "graspers." This design greatly facilitates the accurate positioning of the anatomically oriented device and subsequently ensures the optimal positioning of the valve prosthesis. The device underwent successful animal testing and a first-in-man implantation series for high-risk patients with $\mathrm{AS}$ or $\mathrm{AR} \cdot{ }^{8-10} \mathrm{~A}$ study has already shown satisfactory early outcomes in patients with AS or AR at high risk for open surgery using the new J-Valve system. ${ }^{11}$

\section{MATERIALS AND METHODS \\ Study Design}

From July 2014 to June 2015, patients with isolated aortic valve disease who were referred to Fuwai Hospital (Beijing, China) were enrolled in this study. Surgical risk was assessed using the logistic European System for
Cardiac Operative Risk Evaluation (euroSCORE) II scale for all patients. The inclusion criteria applied in this study were as follows: (1) patients with symptomatic AS with an aortic valve area of $1.0 \mathrm{~cm}^{2}$ or less or a mean transvalvular pressure gradient of $40 \mathrm{~mm} \mathrm{Hg}$ or greater or a peak velocity of $4 \mathrm{~m} / \mathrm{s}$ or greater or AR (grade III-IV) with or without leaflet calcification; (2) an aortic annulus diameter between 19 and $27 \mathrm{~mm}$ as measured on a 3-dimensional computed tomography angiography (CTA) image; (3) New York Heart Association (NYHA) heart function II or greater and a logistic euroSCORE I of $20 \%$ or greater; (4) without significant dilation of the ascending aorta or aortic sinus $(<43 \mathrm{~mm})$. All patients were enrolled consecutively during the trial. Informed consent was obtained from each patient before inclusion. The hospital ethics committee and the Institutional Review Board granted their approval for this study.

Preprocedural transthoracic echocardiography (TTE), transesophageal echocardiography, and 3-dimensional CTA were used to evaluate the patients. Transesophageal echocardiography and TTE were used to measure heart function and valve pathology, including the effective orifice area, the peak and mean transvalvular pressure gradients, and the regurgitation degree/cause. The aortic annulus diameters, ascending aorta diameter, aortic valve calcification degree, and distance between the valve annular level and the coronary ostia were measured on CTA images in mid-systolic phase. Coronary artery disease also was screened for on the basis of the preoperative CTA image. The distance between the valve annular level and the coronary ostia should be greater than $6 \mathrm{~mm}$.

The end points were based on the Valve Academic Research Consortium II criteria for effectiveness. ${ }^{12}$ The primary end point was a combined efficacy end point after 1 year that included all-cause mortality after more than 30 days, failure of current therapy for AS or AR requiring hospitalization for symptoms of valve-related cardiac decompensation, or prosthetic heart valve dysfunction (aortic valve area $<1.2 \mathrm{~cm}^{2}$ and mean aortic valve gradient $>20 \mathrm{~mm} \mathrm{Hg}$ or peak velocity $>3 \mathrm{~m} / \mathrm{s}$, or moderate or severe prosthetic valve regurgitation). Additional primary end points were transvalvular aortic peak pressure gradient, valve migration or dislocation, and the absence of mechanical coronary obstruction.

Secondary end points were analyzed for safety after 6 and 12 months. These end points included cardiovascular mortality; major stroke; lifethreatening, disabling, or major bleeding, acute kidney injury; myocardial infarction; major vascular complications; prosthetic valve thrombosis; prosthetic valve endocarditis; conduction disturbances and cardiac arrhythmias; a necessity for permanent pacemaker implantation; and the absence of mechanical coronary obstruction. To evaluate clinical improvement, the patients were assessed for dyspnea using the NYHA classification.

\section{Surgical Technique}

The J-Valve system comprises a porcine aortic valve attached to a nitinol stent with $3 \mathrm{U}$-shaped graspers encircling the valve stent. Before deployment, the fully released graspers can serve as an anatomically oriented device to achieve "self-positioning" of the valve stent. A 27F delivery catheter (Ausper-AS system, JC Medical Technologies, Suzhou, China) is used during the 2-stage deployment procedure. The flexible tip of the delivery system can be reshaped before the surgery to achieve better angulation between the left ventricular outflow tract and the aortic annulus. With the anchoring mechanism, the prosthesis is partially retrievable and repositionable, thus enabling a balloon redilatation to be performed if necessary (Figure 1).

Four sizes of manufactured prosthesis are available (21, 23, 25, and $27 \mathrm{~mm}$ ), which can be implanted in aortic annuli ranging from 19 to $27 \mathrm{~mm}$. Following the manufacturer's recommendations, 21-, 23-, 25-, and $27-\mathrm{mm}$ prostheses were used for patients with aortic annuli from 19 to $20.9 \mathrm{~mm}, 21$ to $22.9 \mathrm{~mm}, 23$ to $24.9 \mathrm{~mm}$, and 25 to $27 \mathrm{~mm}$, respectively. Slightly oversized $(10 \%)$ devices, based on the same strategy, were selected for patients with AR. The appropriate size was selected according to preoperative analysis of the CTA perimeter-derived aortic annulus diameter. 


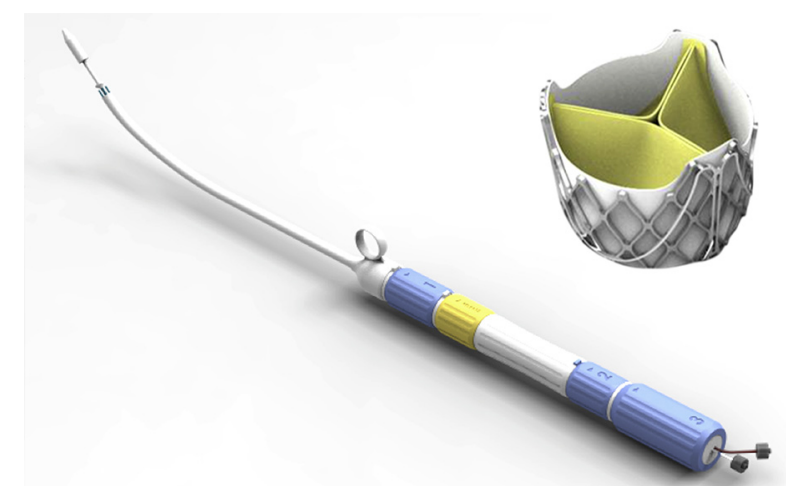

FIGURE 1. The valve and delivery system of the J-Valve system (Jie Cheng Medical Technologies, Suzhou, China).

Transapical implantation of the J-Valve prosthesis was performed under general anesthesia by an interdisciplinary heart team in a hybrid operation room. The implantation procedure was previously reported by Cheng and colleagues. ${ }^{10}$ Video 1 and Figures 2 and 3 show the same procedure.

The coronary blood flow, paravalvular and central regurgitation, transvalvular pressure gradients, and effective valve opening area were controlled by fluoroscopy and echocardiography after all 3 steps. Re-balloon valvuloplasty of the J-Valve system was performed when elevated transvalvular gradients, significant paravalvular leakage, or incomplete opening of the device was observed. The delivery catheter was removed, and ventricular hemostasis was achieved using the purse-string sutures. After insertion of the chest tube, surgical closure of the thoracotomy was performed.

\section{Data Collection and Statistical Analysis}

Patients underwent follow-up examinations including TTE, CTA, electrocardiogram, and NYHA functional class status at the time of hospital discharge, at 30 days, and at 6 and 12 months. Most of the TTEs were performed in-hospital by the same cardiologist following a prespecified examination protocol to ensure comparability. All-cause and cardiovascular mortality were documented during hospitalization and follow-up visits. Other complications, such as procedure failure, paravalvular leakage,

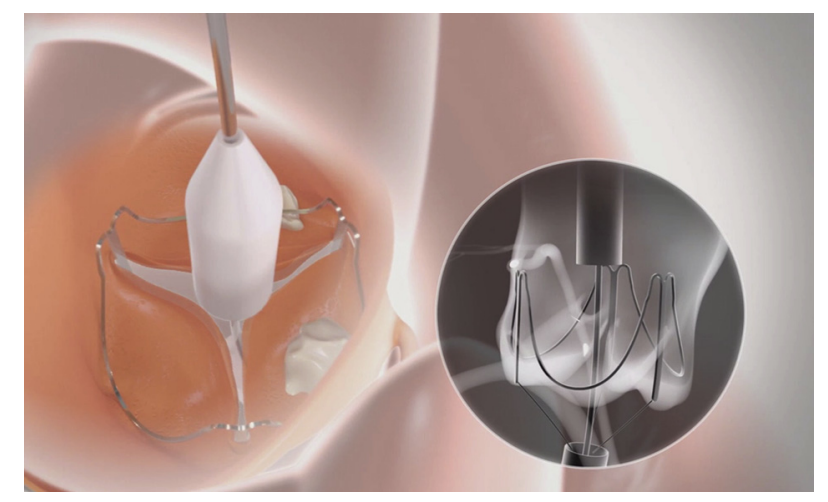

VIDEO 1. Procedure for the implantation of the J-Valve system (Jie Cheng Medical Technologies, Suzhou, China). After the delivery sheath was sent into the supra-annular plan using a transapical approach, 3 graspers were then totally released and pushed gently back into the aortic sinuses. The valve was then retrieved into the annular plane with the aid of the locking device and deployed without rapid ventricular pacing. Video available at: http://www.jtcvsonline.org/article/S0022-5223(17)30564-0/ addons. conduction block, and cerebral vascular event, were recorded during follow-up.

Continuous variables are presented as the means and standard deviations. Categoric variables were assessed as raw counts and percentages. The Wilcoxon matched-pairs signed-rank test was used for comparison of the preoperative and postoperative measurements. Echocardiographic data are presented as medians and interquartile ranges (IQRs). Statistical analyses were performed using statistical analysis software (SPSS version 22.0, IBM, New York, NY). Data were regularly checked for completeness and correctness and were monitored by an independent clinical research organization.

\section{Ethical Considerations}

The study was approved by the local ethical committee in accordance with the principles of the Declaration of Helsinki. All authors had access to the complete dataset and take responsibility for its integrity. All authors have read and agreed to the article as written.

\section{RESULTS}

\section{Patient Demographics and Characteristics}

Between July 2014 and June 2015, a total of 21 patients received transapical TAVI using the J-Valve in Fuwai Hospital. Among them, 17 patients had severe symptomatic AS; the remaining 4 patients had pure or dominant AR. The mean age of the patients was $75.52 \pm 5.22$ years, and $66.7 \%$ $(n=15)$ of the patients were female. The euroSCORE II score was $11.33 \pm 1.28$, the mean logistic euroSCORE I was $31.13 \% \pm 9.68 \%$ in the study cohort, and the mean Society of Thoracic Surgeons-predicted risk of mortality was $12.23 \% \pm 3.90 \%$. Nine patients $(42.9 \%)$ had coronary heart disease; among them, 1 underwent CABG and 1 had previously received a percutaneous coronary intervention. The majority of the patients $(90.5 \%)$ presented with NYHA functional class III/IV. The demographic and baseline characteristics of the patients, including comorbidities, are listed in Table 1.

\section{Preoperative Echocardiographic Results $(n=21)$}

The median preoperative left ventricular ejection fractions (LVEFs) of patients with $\mathrm{AS}$ and $\mathrm{AR}$ were $65.6 \%$ (IQR, 52.15-69.05) and 64.3\% (IQR, 59.7568.25), respectively, and the median aortic annulus diameters were $21 \mathrm{~mm}$ (IQR, 20-23.5) and $24.5 \mathrm{~mm}$ (IQR, 23.25-25), respectively. Patients with AS $(n=17)$ had a median effective valve area of $0.53 \mathrm{~cm}^{2}$ (IQR, 0.485-0.765) and a median transvalvular aortic mean pressure gradient of $57.00 \mathrm{~mm} \mathrm{Hg}$ (IQR, 48.5-75). Patients with AR $(\mathrm{n}=4)$ all had severe AR (Table 2).

\section{Perioperative Data $(\mathbf{n}=\mathbf{2 1})$}

Transapical implantation of the J-Valve prosthesis was successful in 19 of 21 patients (procedural success rate $90.5 \%$, AS $88.2 \%$, AR $100 \%$ ). A second delivery was performed in 1 patient because of dislocation of the valve into the descending aorta. Conversion to open surgical aortic valve replacement was necessary in 2 patients with AS 

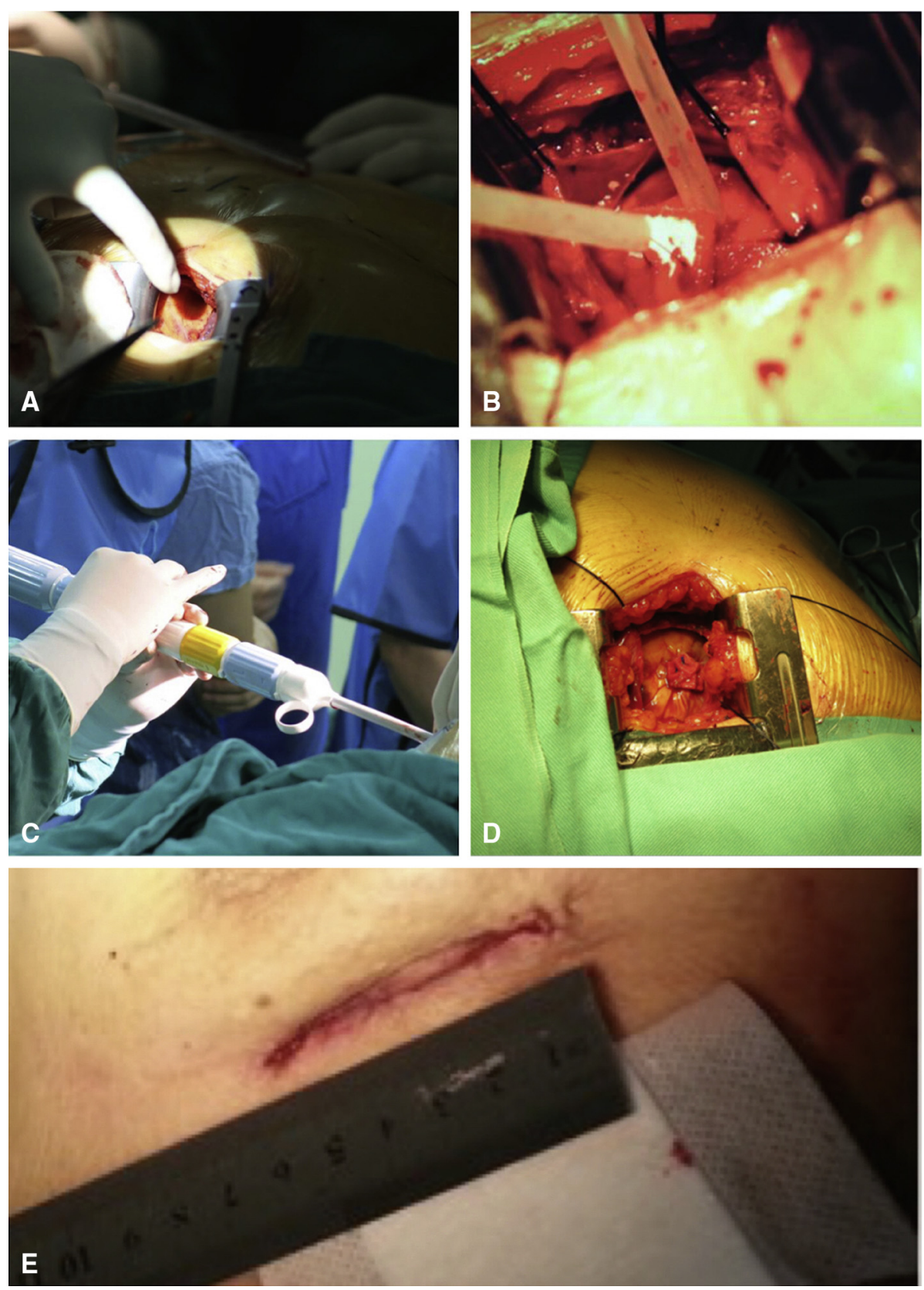

FIGURE 2. Surgical views of the procedure. A, Transapical access is gained via a left lateral minithoracotomy in the fifth or sixth intercostal space. B, Multiple pledged purse-string sutures are placed in the apex of the heart. C, The delivery system is bluntly inserted into the left ventricle. D, The delivery catheter is removed, and ventricular hemostasis is achieved using the purse-string sutures. E, Surgical closure of the thoracotomy.

because of malposition of the graspers. Six 21-mm, six 23$\mathrm{mm}$, five $25-\mathrm{mm}$, and four $27-\mathrm{mm} \mathrm{J}$-Valve prostheses were used. Of these, three 27-mm and 25-mm J-Valves were implanted in the patients with AR. Conduction disturbances and arrhythmias were observed in 1 patient $(4.8 \%)$ with atrioventricular block grade III. Permanent pacemaker implantation was performed only in this patient $(\mathrm{n}=1$; $4.8 \%$ ). Mean intensive care unit stay was $2.05 \pm 1.75$ days. Postoperative echocardiographic follow-up was accomplished before discharge and showed a median LVEF of $62 \%$ (IQR, 59.6-72.9) and a median transvalvular aortic mean pressure gradient of $12 \mathrm{~mm} \mathrm{Hg}$ (IQR, 9-17). Mild paravalvular leakage was observed in 10 patients $(53.6 \%)$, and 9 patients $(47.4 \%)$ showed no paravalvular leakage. No moderate or severe paravalvular leakage was observed $(\mathrm{n}=0 ; 0.00 \%)$. Major bleeding requiring surgical revision occurred in 1 patient $(4.8 \%)$. No other major complications, including coronary obstruction, valvular 

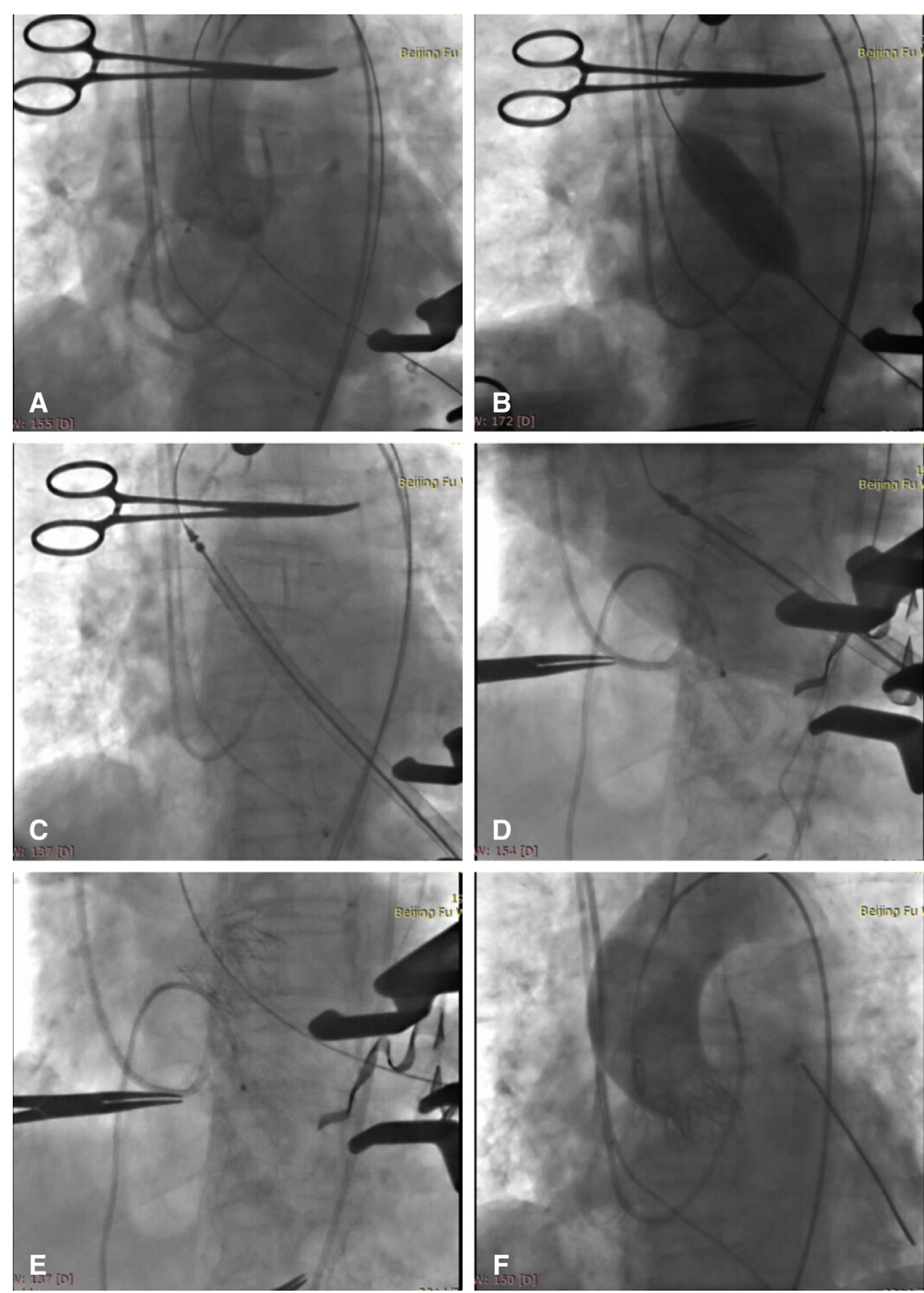

FIGURE 3. Fluoroscopic views of the procedure. A, Angiogram of the aortic root before the procedure. B, Valvuloplasty of the aortic valve using a balloon. C, Delivery of the J-Valve system. D, Release of the 3 graspers. E, Valve deployment. F, Angiogram after the procedure.

thrombosis, perioperative myocardial infarction, and perioperative stroke, were found during hospitalization among the study cohort. No major vascular complications were observed (Table 3).

Thirty-day mortality was $4.8 \%(\mathrm{n}=1)$; the cause of death was a sudden malignant arrhythmia and cardiac failure. No patients died intraoperatively.

\section{Echocardiographic Characteristics After 6 and 12 Months $(\mathbf{n}=18)$}

Echocardiographic examination was performed at 1 year for primary end points in 18 patients $(85.7 \%) ; 1$ case of death $(4.8 \%)$ and 2 cases $(9.5 \%)$ of conversion to surgery were excluded from the original cohort. No additional mortality occurred during the follow-up.

Median transvalvular aortic mean pressure gradient in patients with AS was $15 \mathrm{~mm} \mathrm{Hg}$ (IQR, 9.75-25.25) at 6 months and $17 \mathrm{~mm} \mathrm{Hg}$ (IQR, 11-26.5) at 12 months after implantation. The median effective aortic valve area was $1.51 \mathrm{~cm}^{2}$ (IQR, 1.33-1.73) after 6 months and $1.45 \mathrm{~cm}^{2}$ (IQR, 1.26-1.61) after 1 year $(\mathrm{n}=14)$.

At the 12-month follow-up, only 2 patients $(11.1 \%)$ with AS reported mild paravalvular regurgitation; the remaining 16 patients reported no paravalvular regurgitation. No 
TABLE 1. Patient demographic and baseline characteristics

\begin{tabular}{lc}
\hline \multicolumn{1}{c}{ Patients } & $\mathbf{n}=\mathbf{2 1}$ \\
\hline Age (y, mean \pm SD) & $75.52 \pm 5.22$ \\
Female (n, \%) & $15(66.7)$ \\
Body mass index $\left(\mathrm{kg} / \mathrm{m}^{2}\right)$ & $24.39 \pm 5.22$ \\
Systemic hypertension (n, \%) & $17(81.0)$ \\
Coronary artery disease (n, \%) & $9(42.9)$ \\
$\quad$ Angina (n, \%) & $9(42.9)$ \\
$\quad$ Previous CABG (n, \%) & $1(4.8)$ \\
$\quad$ Previous PCI (n, \%) & $1(4.8)$ \\
NYHA functional class III/IV (n, \%) & $19(90.5)$ \\
Previous pacemaker (n, \%) & $0(0.0)$ \\
Previous AV block (n, \%) & $0(0.0)$ \\
Hyperlipidemia (n, \%) & $16(76.2)$ \\
Atrial fibrillation (n, \%) & $4(19.0)$ \\
COPD (n, \%) & $4(19.0)$ \\
Cerebrovascular disease (n, \%) & $8(38.1)$ \\
PAH (n, \%) & $0(0.0)$ \\
Renal dysfunction (n, \%) & $0(0.0)$ \\
Liver dysfunction (n, \%) & $0(0.0)$ \\
Anemia (n, \%) & $5(23.8)$ \\
euroSCORE II & $11.33 \pm 1.28$ \\
Logistic euroSCORE I (\%) & $31.13 \pm 9.68$ \\
STS mortality (\%) & $12.23 \pm 3.90$ \\
\hline Continuous variables are expressed as the means \pm standard deviations. Categoric \\
variables are presented as raw numbers and percentages. SD, Standard deviation; \\
CABG, coronary artery bypass grafting; PCI, percutaneous coronary intervention; \\
NYHA, New York Heart Association; AV, aortic valve; COPD, chronic obstructive \\
pulmonary disease; PAH, pulmonary artery hypertension; euroSCORE, European \\
System for Cardiac Operative Risk Evaluation; STS, Society of Thoracic Surgeons. \\
\end{tabular}

moderate or severe regurgitation was reported. Most patients $(\mathrm{n}=15)$ showed no transvalvular regurgitation; only 3 patients with AS reported mild transvalvular leakage. Median LVEF was $63.4 \%$ (IQR, 57.4-67.8) after 6 months and 64\% (IQR, 59.8-69.5) after 1 year (Table 4, Figures 4-7).

\section{Clinical End Points}

The combined primary efficacy end points after 12 months included all-cause mortality after more than 30 days and failure of current therapy for AS or AR

TABLE 2. Preoperative echocardiographic results $(n=21)$

\begin{tabular}{lcc}
\hline \multicolumn{1}{c}{ Aortic valve pathology } & $\mathbf{A S}(\mathbf{n}=\mathbf{1 7})$ & $\mathbf{A R}(\mathbf{n}=\mathbf{4})$ \\
\hline Effective valve area $\left(\mathrm{cm}^{2}\right)$ & $0.53(0.485-0.765)$ & - \\
& $0.62 \pm 0.17 \mathrm{~cm}^{2 *}$ & \\
& $57.00(48.5-75)$ & - \\
Transvalvular aortic mean & $61 \pm 15^{*}$ & \\
$\quad$ pressure gradient $(\mathrm{mm} \mathrm{Hg})$ & $21(20-23.5)$ & $24.5(23.25-25)$ \\
Aortic annulus diameter (mm) & $65.6(52.15-69.05)$ & $64.3(59.75-68.25)$ \\
LVEF (\%) & - & 0 \\
Regurgitation degree (n) & - & 4 \\
Grade III & - & \\
Grade IV & & \\
\hline
\end{tabular}

Echocardiographic data are presented as median and IQR. AS, Aortic stenosis; $A R$, aortic regurgitation; $L V E F$, left ventricular ejection fraction. *Data are presented as the mean \pm standard deviation.
TABLE 3. Perioperative data $(n=21)$

\begin{tabular}{lc} 
Procedure details $(\mathrm{n}=21)$ & \\
21-mm prosthesis (n, \%) & $6(28.6)$ \\
23-mm prosthesis (n, \%) & $6(28.6)$ \\
25-mm prosthesis (n, \%) & $5(23.8)$ \\
27-mm prosthesis (n, \%) & $4(19.0)$ \\
Successful implantation (n, \%) & $19(90.5)$ \\
Second implantation (n, \%) & $1(4.8)$ \\
Postdilation (n, \%) & $16(76.2)$ \\
Conversion to surgical aortic valve replacement (n, \%) & $2(9.5)$ \\
Coronary obstruction (n, \%) & $0(0)$ \\
Third-degree AV block or pacemaker required (n, \%) & $1(4.8)$ \\
Postoperative results (n = 19) & \\
Days in intensive care unit (d) & $2.05 \pm 1.75$ \\
In-hospital days & $19.11 \pm 5.99$ \\
LVEF postoperative (\%) & $62(59.6-72.9)$ \\
Transvalvular aortic mean pressure gradient & $12(9-17)$ \\
$\quad$ (mm Hg) (AS, $\mathrm{n}=15)$ & \\
Paravalvular leakage & \\
Zero to trace (n, \%) & $9(47.4)$ \\
Mild (n, \%) & $10(53.6)$ \\
Moderate (n, \%) & $0(0)$ \\
Severe (n, \%) & $0(0)$ \\
Valvular thrombosis (n, \%) & $0(0)$ \\
Perioperative myocardial infarction (n, \%) & $0(0)$ \\
Major bleeding requiring surgical revision (n, \%) & $1(4.8)$ \\
Major vascular complication (n, \%) & $0(0)$ \\
Overall 30-d mortality & $1(4.8)$ \\
\hline Cons & \\
\hline
\end{tabular}

Continuous variables are expressed as the mean \pm standard deviation. Categoric variables are presented as raw numbers and percentages. Echocardiographic data are presented as medians and IQR. $A V$, Atrioventricular; $L V E F$, left ventricular ejection fraction; $A S$, aortic stenosis.

requiring hospitalization for symptoms of valve-related cardiac decompensation. At the 12-month follow-up, there were no cases of death after more than 30 days and no cases of rehospitalization due to valve dysfunction. However,

TABLE 4. Echocardiographic characteristics after 12 months $(n=18)$

\begin{tabular}{lcc}
\hline & AS $(\mathbf{n}=\mathbf{1 4})$ & AR $(\mathbf{n}=\mathbf{4})$ \\
\hline Transvalvular aortic mean pressure & $17(11-26.5)$ & - \\
gradient (mm Hg) & $18 \pm 9^{*}$ & \\
Effective aortic valve area $\left(\mathrm{cm}^{2}\right)$ & $1.45(1.25-1.61)$ & - \\
& $1.52 \pm 0.35^{*}$ & \\
Paravalvular regurgitation (n, \%) & & \\
Zero to trace & $12(66.7)$ & $4(22.2)$ \\
Mild & $2(11.1)$ & 0 \\
Moderate & 0 & 0 \\
Severe & 0 & 0 \\
Transvalvular regurgitation (n, \%) & $11(61.1)$ & $4(22.2)$ \\
Zero to trace & $3(16.7)$ & 0 \\
Mild & 0 & 0 \\
Moderate & 0 & 0 \\
Severe & $64(59.8-69.5)$ & \\
LVEF $(\%)$ &
\end{tabular}

Categoric variables are presented as raw numbers and percentages. Echocardiographic data are presented as median and IQR. $A S$, Aortic stenosis; $A R$, aortic regurgitation; $L V E F$, left ventricular ejection fraction. *Data are presented as mean \pm standard deviation. 
Mean gradient of patients with AS, $n=14$

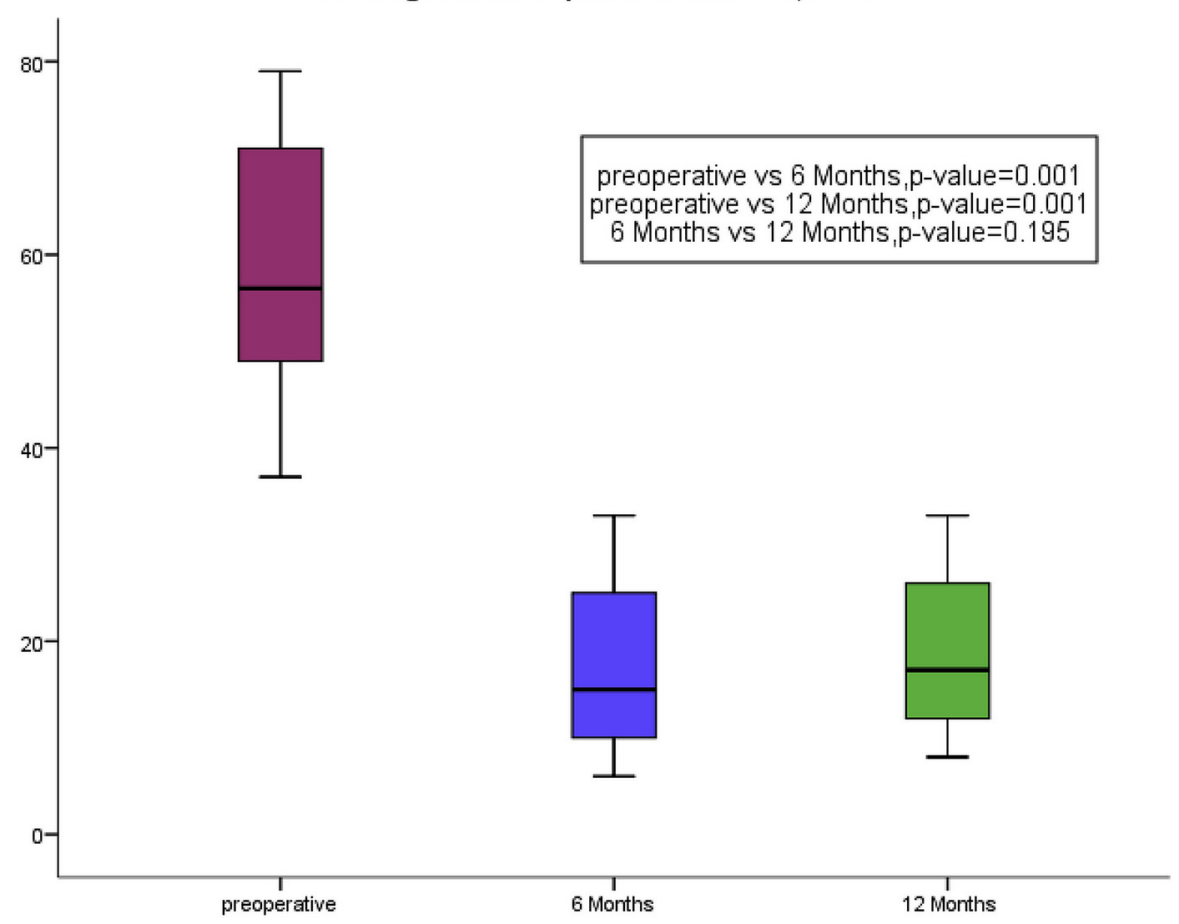

FIGURE 4. Boxplots comparing mean gradients in 14 patients with AS preoperatively and at 6 and 12 months postoperatively. The preoperative and 6month postoperative values significantly differed, as did the preoperative and 12-month postoperative values (each $P=.001$ ). The 6- and 12 -month postoperative values did not significantly differ $(P=.195)$. $A S$, Aortic stenosis.

criteria for the combined efficacy end point after 1 year were met in 5 patients who had transvalvular mean gradients greater than $20 \mathrm{~mm} \mathrm{Hg}$. None of these patients reported any discomfort, and all refused hospitalization for further aggressive therapy. In addition, all 18 patients who finished 1-year follow-up reported improvement in NYHA classifications; among them, 15 patients $(83.3 \%)$ reported an improvement of at least 2 NYHA classes and the remaining 3 patients $(17.7 \%)$ reported an improvement of 1 NYHA class. No patients reported a deterioration of the dyspnea. Preoperatively, most patients were considered NYHA class III, and most were considered class II after the operation (Table 5, Figure 7).

At the end of the 12-month follow-up, 1 patient (5.6\%) reported a stroke that required hospitalization. No cases of major vascular complications, prosthetic valve thrombosis, myocardial infarction, or clinically significant valve migration or dislocation were observed after 6 and 12 months. The combined ratio of successful implantation and absence of adverse events in our cohort $(\mathrm{n}=21)$ was $76.19 \%$.

\section{DISCUSSION}

In this study, we present the first midterm outcomes of patients with AS or AR using the J-Valve system in Fuwai Hospital. The results obtained confirm the safety and feasibility of the prosthesis at 1 year, considering the satisfactory early results published. ${ }^{1}$

The procedure success ratios for patients with AS and AR were $88.2 \%$ and $100 \%$, respectively, probably due to the design concept of these anatomically oriented devices, which featured 3 U-shaped "graspers" encircling the valve frame. The surgeons obtained direct tactile feedback by pulling over these devices during deployment to actively determine the correct position for the valve prosthesis; this tremendously simplified the procedure and minimized the risk of prosthesis malposition, embolization, and coronary ostial obstruction. Other types of second-generation prostheses, such as the JenaValve and Medtronic Engager valves, showed similar results. ${ }^{3,13-15}$ The study showed a more favorable outcome for patients with noncalcified AR due to the extra-axial fixation force provided by the clip-fixation between the valve stent and the anatomically oriented device. $^{3,5,8,9}$ It was reported recently that the learning curve for transapical TAVR was 30 to 45 cases with a device success of $90 \%$, and technical efficiency was achieved without compromising patient safety. For these first 21 cases in our center, the successful implantation rate was $90.5 \%$, thus providing satisfactory patient safety. ${ }^{16}$ Furthermore, more than mild paravalvular leakage was $100 \%$ absent in those with AS and those with AR, and no patient reported significant postprocedural 
EVA of patients with $A S, n=14$

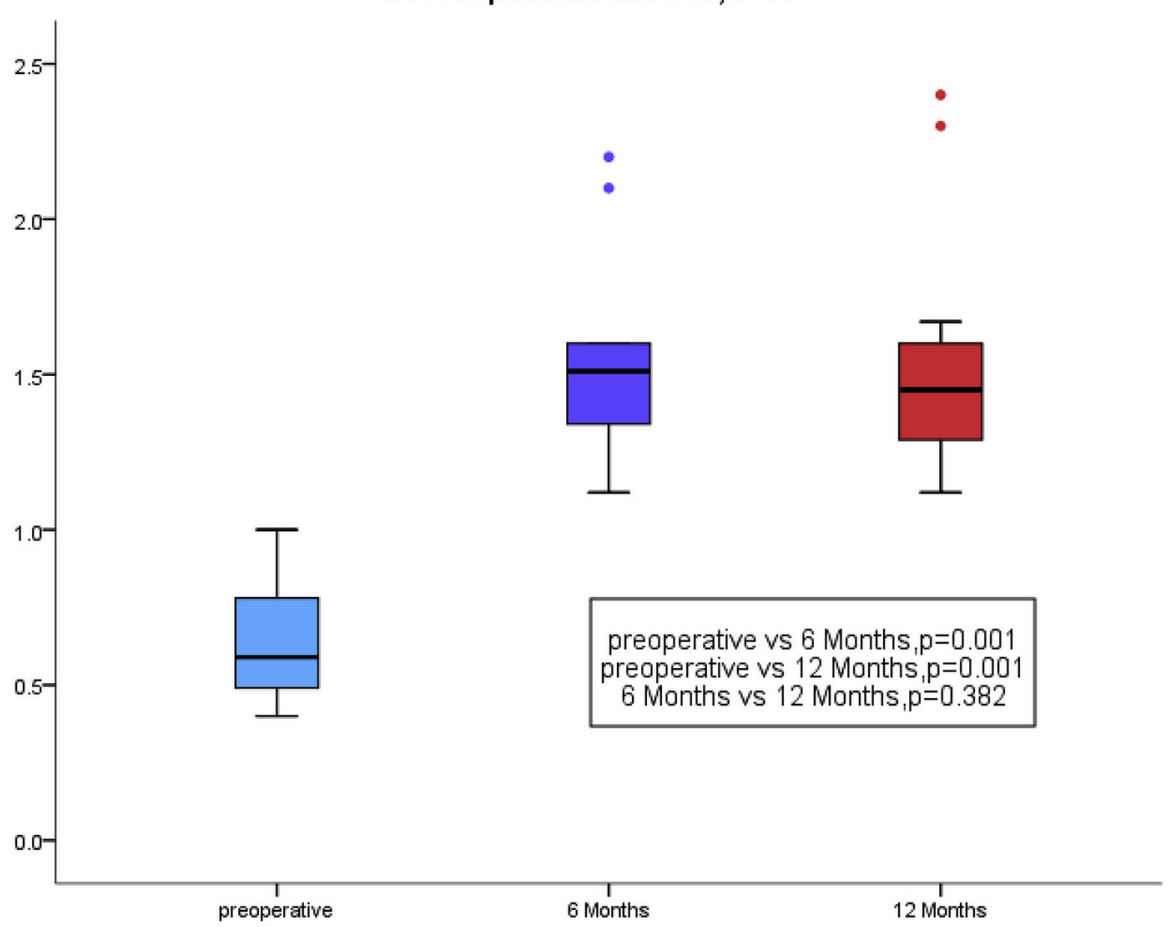

FIGURE 5. Boxplots comparing the effective valve area in 14 patients with AS preoperatively and 6 and 12 months postoperatively. The preoperative and 6-month postoperative values significantly differed, as did the preoperative and 12-month postoperative values (each $P=.001$ ). The 6-and 12-month postoperative values did not significantly differ $(P=.382)$. EVA, Effective valve area; $A S$, aortic stenosis.

$\mathrm{AR}$ in our cohort. The risk for permanent pacemaker implantation was lower $(4.8 \%$ ) than that obtained using the JenaValve $(6.4 \%-9.1 \%)^{3,13,14}$ because of the reduced radial forces in the aortic annulus, which were facilitated by the low stent profile design and the leaflet clip mechanism.

The 30-day mortality and 1-year all-cause mortality were both $4.8 \%$ and were lower than corresponding values for patients undergoing transapical TAVI with the second-generation devices Engager (Medtronic), JenaValve, and Symetics (Acurate) $(26.1 \%, 32.1 \%$, and $12.4 \%$ at 1 year, respectively). ${ }^{17}$ This favorable result should be interpreted cautiously because of the limited statistical power provided by the small sample size of 21 patients.

The echocardiographic follow-up regarding parameters, including the transvalvular mean gradient, effective valve area, and LVEF, showed excellent midterm results (Figures 4-7). For patients with AS, there was an increase in effective valve area from $0.62 \pm 0.17 \mathrm{~cm}^{2}$ to $1.52 \pm 0.35 \mathrm{~cm}^{2}$ and a decrease in transvalvular mean gradient from $61 \pm 15 \mathrm{~mm} \mathrm{Hg}$ to $18 \pm 9 \mathrm{~mm} \mathrm{Hg}$. These values were comparable to those obtained in previous studies, such as transapical TAVI with the Edwards Sapien $\left(0.6 \pm 0.2 \mathrm{~cm}^{2}\right.$ to $1.6 \pm 0.5 \mathrm{~cm}^{2}$, and 47.2 $\pm 18.9 \mathrm{~mm} \mathrm{Hg}$, to $11.5 \pm 3.9 \mathrm{~mm} \mathrm{Hg}$, respectively) ${ }^{18}$ and the JenaValve system $\left(0.75 \pm 0.14 \mathrm{~cm}^{2}\right.$ to $1.84 \pm 0.57 \mathrm{~cm}^{2}$ and $49.43 \pm 8.44 \mathrm{~mm} \mathrm{Hg}$ to $12.00 \pm 5.53 \mathrm{~mm} \mathrm{Hg}$, respectively). ${ }^{7}$ Although the LVEF of all patients showed no significant change at 6 and 12 months, the NYHA class improvement showed a more favorable result (15 patients [83.3\%] reported an improvement of 2 NYHA classes, and the remaining 3 patients [17.7\%] reported an improvement of 1 NYHA class) than that obtained using the JenaValve system (1 patient [4.76\%] reported an improvement of 2 NYHA classes, 12 patients [57.14\%] reported an improvement of 1 NYHA class, and 8 patients [38.1\%] reported no improvement), ${ }^{7}$ given the inferior preoperative echocardiographic results.

\section{Study Limitations}

The main limitation of this study was the limited number of patients; thus, the confirmation of the safety and validity of the prosthesis was less powerful. In addition, there was an initial learning curve period, during which the results could have been affected. Although our experience and midterm outcome were promising, larger prospective studies with longer follow-ups are necessary to fully evaluate the safety and efficacy of the J-Valve system.

\section{CONCLUSIONS}

In these first midterm results reported for the secondgeneration transapical TAVI system, the J-Valve system 


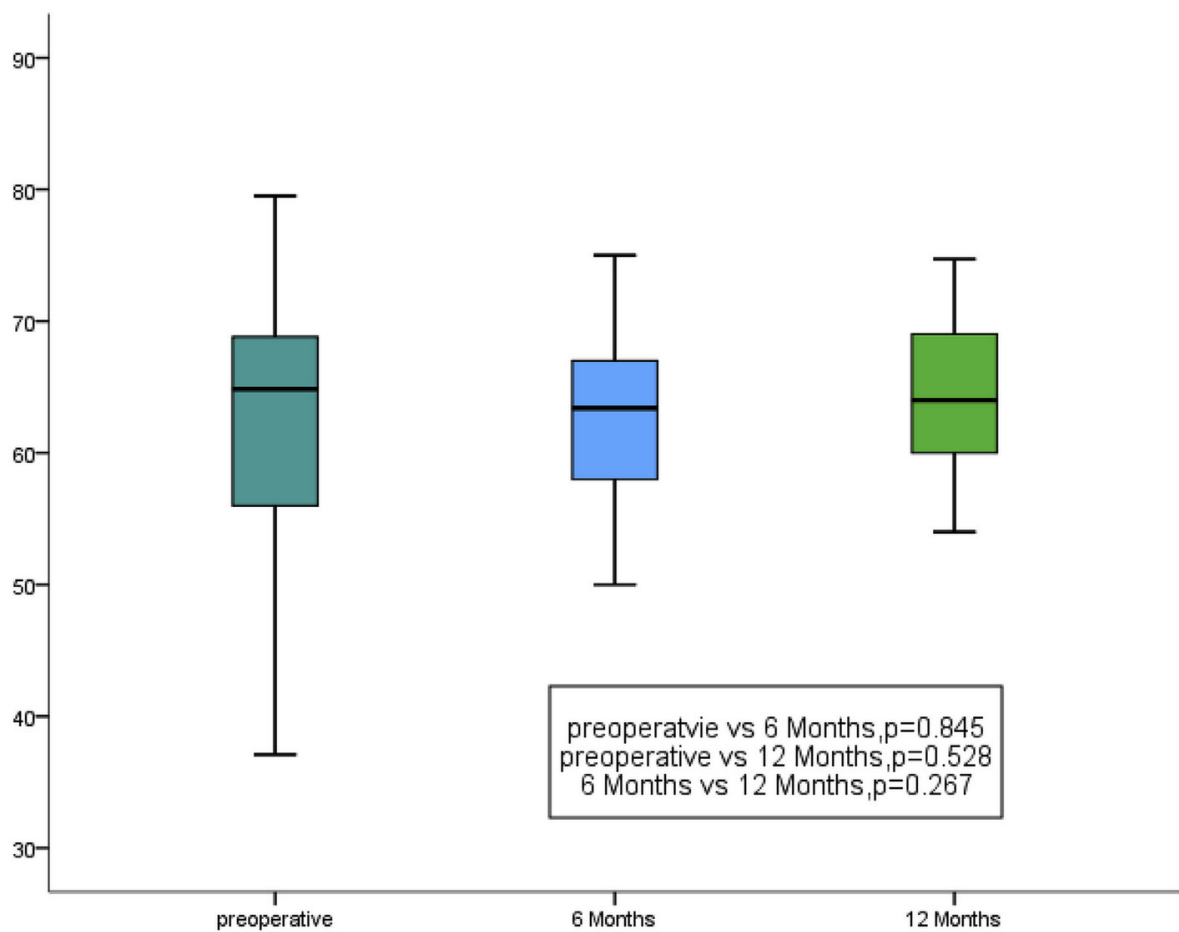

FIGURE 6. Boxplots comparing LVEF in 18 patients preoperatively and at 6 and 12 months postoperatively. The values did not significantly differ between the groups (preoperative vs 6 months postoperative: $P=.845$; preoperative vs 12 months postoperative: $P=.528 ; 6$ months postoperative vs 12 months postoperative: $P=.267)$. $L V E F$, Left ventricular ejection fraction.

showed excellent performance regarding echocardiographic parameters including transvalvular gradient, paravalvular regurgitation, and effective aortic valve area after a 12-month follow-up. Moreover, the postoperative NYHA classification showed significant clinical improvement over the preoperative scores, and the secondary safety end points also returned favorable results. Thus, this study provides strong evidence for the safety and efficacy of the J-Valve system, which supplement the previously published positive early results. Further studies with larger numbers of patients are warranted to confirm these results.

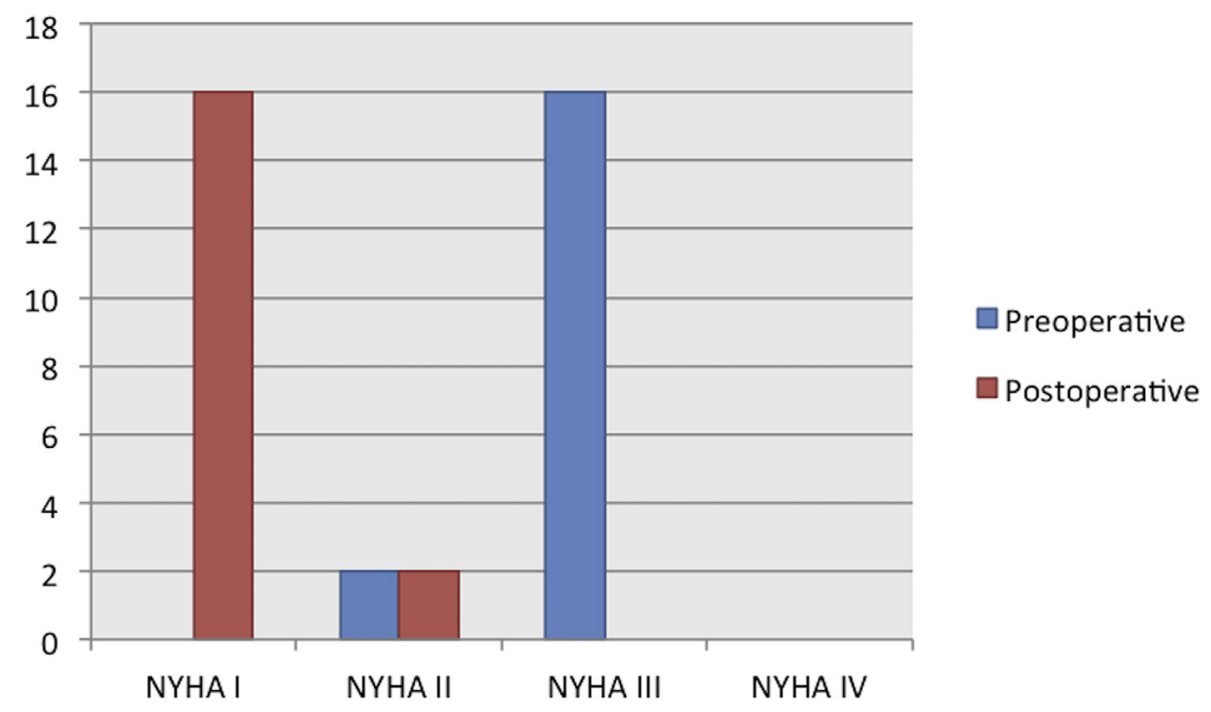

FIGURE 7. NYHA classifications recorded preoperatively and postoperatively after 12 months. NYHA, New York Heart Association. 
TABLE 5. New York Heart Association classification for dyspnea $(\mathbf{n}=18)$

Functional improvement assessment by NYHA functional classification

\begin{tabular}{lc}
\hline No improvement $(\mathrm{n}, \%)$ & $0(0.0)$ \\
Improvement of 1 category (n, \%) & $3(17.7)$ \\
Improvement of 2 categories (n, \%) & $15(83.3)$ \\
Deterioration of functional assessment (n, \%) & $0(0.0)$ \\
\hline
\end{tabular}

Categoric variables are presented as raw numbers and percentages. NYHA, New York Heart Association.

\section{Conflict of Interest Statement}

Authors have nothing to disclose with regard to commercial support.

\section{References}

1. Cribier A, Eltchaninoff H, Bash A, Borenstein N, Tron C, Bauer F, et al. Percutaneous transcatheter implantation of an aortic valve prosthesis for calcific aortic stenosis: first human case description. Circulation. 2002;106:3006-8.

2. Leon MB, Smith CR, Mack M, Miller DC, Moses JW, Svensson LG, et al. Transcatheter aortic-valve implantation for aortic stenosis in patients who cannot undergo surgery. N Engl J Med. 2010;363:1597-607.

3. Seiffert M, Bader R, Kappert U, Rastan A, Krapf S, Bleiziffer S, et al. Initial German experience with transapical implantation of a second-generation transcatheter heart valve for the treatment of aortic regurgitation. JACC Cardiovasc Interv. 2014;7:1168-74.

4. Wendt D, Kahlert P, Pasa S, El-Chilali K, Al-Rahid F, Tsagakis K, et al. Transapical transcatheter aortic valve for severe aortic regurgitation: expanding the limits. JACC Cardiovasc Interv. 2014;7:1159-67.

5. Kiefer P, Seeburger J, Mohr FW, Holzhey DM. Transcatheter aortic valve replacement for isolated aortic valve insufficiency: experience with the Engager valve. J Thorac Cardiovasc Surg. 2014;147:e37-8.

6. Sinning JM, Hammerstingl C, Vasa-Nicotera M, Adenauer V, Lema Cachiguango SJ, Scheer AC, et al. Aortic regurgitation index defines severity of peri-prosthetic regurgitation and predicts outcome in patients after transcatheter aortic valve implantation. J Am Coll Cardiol. 2012;59:1134-41.

7. Reuthebuch O, Koechlin L, Kaufmann BA, Kessel-Schaefer A, Gahl B, Eckstein FS. Transapical transcatheter aortic valve implantation using the JenaValve: a one-year follow-up. J Thorac Cardiovasc Surg. 2015;63:493-500.
8. Zhu D, Hu J, Meng W, Guo Y. Successful transcatheter aortic valve implantation for pure aortic regurgitation using a new second-generation self-expanding J-Valve ${ }^{\mathrm{TM}}$ system — the first in-man implantation. Heart Lung Circ. 2015;24: 411-4.

9. Zhu D, Chen Y, Zhang J, Hu J, Guo Y. Transapical implantation of a new secondgeneration transcatheter heart valve in patients with pure aortic regurgitation: a preliminary report. Interact Cardiovasc Thorac Surg. 2015;20:860-2.

10. Cheng J, Chen M, Zhu D, Zhang J, Hu J, Guo Y. Successful trans-apical aortic valve implantation for a high risk patient with aortic stenosis using a new second-generation TAVI device- J-Valve ${ }^{\mathrm{TM}}$ system. J Cardiothorac Surg. 2015;10:5.

11. Zhu D, Chen Y, Guo Y, Hu J, Zhang J, Wei X, et al. Transapical transcatheter aortic valve implantation using a new second-generation TAVI system-J-Valve ${ }^{\mathrm{TM}}$ for high-risk patients with aortic valve diseases: Initial results with 90-day follow-up. Int J Cardiol. 2015;199:155-62.

12. Kappetein AP, Head SJ, Généreux P, Piazza N, van Mieghem NM, Blackstone EH, et al. Updated standardized endpoint definitions for transcatheter aortic valve implantation: the Valve Academic Research Consortium-2 consensus document. J Thorac Cardiovasc Surg. 2013;145:6-23.

13. Treede H, Mohr FW, Baldus S, Rasten A, Ensminger S, Arnold M. Transapical transcatheter aortic valve implantation using the JenaValveTM system: acute and 30-day results of the multicentre CE-mark study. Eur J Cardiothorac Surg. 2012;41:e131-8.

14. Falk V, Walther T, Schwammenthal E, Strauch J, Aicher D, Wahlers T, et al. Transapical aortic valve implantation with a self-expanding anatomically oriented valve. Eur Heart J. 2011;32:878-87.

15. Holzhey D, Linke A, Treede H, Baldus S, Bleiziffer S, Wagner A, et al. Intermediate follow-up results from the multicenter engager European pivotal trial. Ann Thorac Surg. 2013;96:2095-100.

16. Suri RM, Minha S, Alli O, Waksman R, Rihal CS, Satler LP, et al Learning curves for transapical transcatheter aortic valve replacement in the PARTNER-I trial: technical performance, success, and safety. J Thorac Cardiovasc Surg. 2016;152:773-80.e14.

17. Seiffert M, Conradi L, Kloth B, Koschyk D, Schirmer J, Schnabel RB, et al. Single-centre experience with next-generation devices for transapical aortic valve implantation. Eur J Cardiothorac Surg. 2015;47:39-45.

18. Lefèvre T, Kappetein AP, Wolner E, Nataf P, Thomas M, Schaechinger V, et al One year follow-up of the multi-centre European PARTNER transcatheter hear valve study. Eur Heart J. 2011;32:148-57.

Key Words: J-Valve system, midterm outcomes, transapical, transcatheter aortic valve implantation 